\title{
Antidiabetic and Antioxidant Activities of Crinum jagus Extracts on Induced Diabetes Rats MACAPOS 1
}

\author{
Clémence Mvongo ${ }^{1, a}$, Adamou Mfopa ${ }^{2, b}$, René Kamgang ${ }^{1,2, c *}$, \\ Jean-Louis Essame Oyono ${ }^{2, d}$
}

\author{
${ }^{1}$ Animal Physiology Laboratory, Faculty of Science, University of Yaoundé I, Cameroon. \\ ${ }^{2}$ Laboratoryof Endocrinology and Radioisotopes, Institute of Medical Research and Medicinal \\ Plants Studies (IMPM), Yaoundé, Cameroon. \\ E-mail address: ${ }^{a} m v o n g o . c l e m e n c e @ y a h o o . f r,{ }^{b}$ adam_mfopa@yahoo.fr, ${ }^{\mathrm{c*}}$ gemskruy@yahoo.fr, \\ djessameoyono@yahoo.com
}

Keywords: Crinum jagus, diabetic rat MACAPOS 1, antioxidant parameters, glycemia.

\begin{abstract}
The antioxidant and antidiabetic activities of aqueous and the hydroethanolic extracts of C. jagus were investigated on diabetic rats MACAPOS 1. Diabetes was induced on 6-8 weeks old wistar rats with high sugar diet (HSD) associated, one month after the beginning of the HSD, with dexamethasone (DXM) injection ( $25 \mu \mathrm{g} / \mathrm{kg}$ once every 2 days during 3 weeks). During 50 days, diabetic rats orally received Metformine $(38 \mathrm{mg} / \mathrm{kg} \mathrm{bw}), C$. jagus hydroethanolic $(75,150 \mathrm{mg} / \mathrm{kg}$ $\mathrm{bw})$ or aqueous $(150 \mathrm{mg} / \mathrm{kg} \mathrm{bw})$ extracts. Treatment with extracts caused significant $(\mathrm{P}<0.01)$ decrease in fasting glycemia, creatinemia, proteinuria, urine volume with concomitant increase in creatinuria, proteinemia, superoxide dismutase, catalase and thiol proteins. C. jagus extracts restored the imbalance of seric and urinary electrolytes, and significantly $(\mathrm{P}<0.01)$ increased peripheral sensibility to pain; the hydroethanolic extract was, in a dose dependant manner, more effective than aqueous extract and metformine. These results indicated that $C$. jagus extracts could possess antioxidant and antidiabetic activities on MACAPOS 1 diabetic rats, and could also improve renal and neurological diabetes damage. The results thus support the use of C. jagus in African folk medicine, mostly in diabetes mellitus treatment and likely its complications.
\end{abstract}

List of abbreviations: $C$. jagus: Crinum jagus; Cjh: Crinum jagus ethanolic extract; Cja: Crinum jagus aqueous extract; Met: metformine; NC: normal control (group); DC: diabetic control (group); HSD: high sugar diet; DXM: dexamethasone; ROS: reactive oxygen species; bw: body weight; SOD: superoxide dismutase; CAT: catalase.

\section{Introduction}

Diabetes is considered to be one of the five leading causes of death worldwide. The number of people suffering from this disease worldwide is increasing at an alarming rate and the developing countries are the most affected. In the world, 382 million people have been diagnosed with diabetes in 2013 and 592 million people could have the disease by the year 2035. In Cameroon, about 498 thousands adults between 20 - 79 years old were estimated with diabetes in 2013 representing $5.90 \%$ of total diabetic potential in the world [1].Diabetes is a non-communicable disease characterized by chronic hyperglycemia associated with carbohydrate, protein and fat disordered metabolism resulting from completed or relative defects in insulin secretion and insulin action or both [2,3]. It is a pathologic condition, associated with the generation of reactive oxygen species (ROS) which causes oxidative damage to heart, kidney, eyes, nerves, liver, blood vessels, immunological and gastrointestinal system[4]. Hyperglycemia not only generates more ROS, but also attenuates antioxidative mechanisms through nonenzymatic glycosylation of antioxidant enzymes. The elevated ROS and the simultaneous decline in antioxidative defense mechanisms observed in uncontrolled hyperglycemia condition could lead to the development of serious complications such as: cardiovascular diseases, retinopathy, nephropathy and neuropathy [4,5]. As the knowledge of diabetes heterogeneity increases, more appropriate therapy is needed. Then, 
treating both oxidative stress and hyperglycemia together may be the benefic approach to regress diabetes and its complications. Although quite effective, current diabetes clinical treatment methods can have undesirable side effects and contraindications. In addition, continuous use of current medications may constitute an economic burden on the user [6]. Traditional antidiabetic plants might provide new oral antidiabetic compounds which can counter the high cost and poor availability of the current medicines for many rural populations in developing countries [7]. Crinum jagus (Amaryllidaceae) is a plant widely used in Africa as antitumoral, antiviral, antiparasitary and immunostimulator. It is also used against mental trouble and snake bite [8]. According to traditional medicine practitioners in the Western Region of Cameroon, this plant is used as antidiabetic, antiobesity, antidiarrheoal remedy and also against poison. To ascertain the folkloric claim of antidiabetic use of this plant, the present study was designed to investigate Antidiabetic and antioxidant activities of Crinum jagus (aqueous and hydroethanolic extracts) on diabetic rats MACAPOS 1.

\section{Material and Methods}

\section{Plant extracts}

Fresh Crinum jagus plants were collected from Batié (Western Region of Cameroon) during the month of April. The species was confirmed bythe National Herbarium of Yaounde (Cameroon), with the voucher specimens HNC 14049. The whole plant was cleaned, sliced into small pieces, shade dried and powdered. This powder was subjected to aqueous and hydroethanolic extractions.For each extract, 500 grams of the powder were macerated in $3 \mathrm{~L}$ of boiled water or ethanol/water (1:4) mixture, for 48 hours (with occasional stirring)at room temperature. After filtration, the water filtrate was dehydrated in a hot air oven; the residue was re-macerated for 48 hours, filtered and dehydrated and the whole dried aqueous extract obtained was weighed (91.4 g). The residue of the ethanol/water mixture, after filtration, was re-macerated for 48 hours and filtered. The 2 filtrates were pooled, concentrated in a rotary evaporator at $40^{\circ} \mathrm{C}$ and dehydrated to yield $145.8 \mathrm{~g}$ of dry dark hydro-ethanolic extract.The hydroethanolic and aqueous extracts were kept in a well-closed container under refrigerated conditions until use.

\section{Animals of experiment}

For the experiment Male albino Wistar rats (6-8 weeks old) were raised in the animal house of the Faculty of Science of the University of Yaounde I (Cameroon) under natural conditions of light and temperature, with free access to water and regular rodent chow. The animals were acclimatized to laboratory condition for one week before the experimentstarts. Before testing the blood glucose level, the rats were fasted overnight but had free access to water. Animal housing and in vivo experiments were performed according to the Guidelines of the European Union directive on Ethical Evaluation of Animal Experiments (CEE Council 86/609) [9] and ethically approved by the Institutional Committee of the Ministry of Scientific Research and Innovation of Cameroon.

\section{Diabetes induction}

To induce type 2 diabetes, the rats were submitted to high sugar diet (HSD), also received per os $0.8 \mathrm{~g} / \mathrm{kg}$ of dextrose (GwaudanLaviretteetCie, Glucose pure Anhydre) and $4 \mathrm{~g} / \mathrm{kg}$ of sucrose (SOSUCAM, Bandjock-Cameroon) every two days [10]. In order to reduce the duration of diabetes induction, the animals received, one month after the beginning of HSD, the dexamethasone (DXM: $25 \mu \mathrm{g} / \mathrm{kg}$ bwi.m.of Dexamethasone RotexMedica Laboratory, Germany) once every 2 days during 3 weeks. After 10 weeks of diet, the animals with fasting total blood glycemia $\geq 126 \mathrm{mg} / \mathrm{dLwere}$ considered as diabetic and were selected for the next stage of experiment.

\section{Antidiabetic activity of the plant extracts}

The rats were divided into 6 groups of 5 animals each: normal controls (NC), diabetic controls (DC), diabetic rats treated with Metformine $(38 \mathrm{mg} / \mathrm{kg}$ bw: Met38), diabetic rats treated with $75,150 \mathrm{mg} / \mathrm{kg}$ bw of $C$. jagushydroethanolic extract (Cjh75,Cjh150)and diabetic rats treated with $150 \mathrm{mg} / \mathrm{kg}$ bw of $C$. jagus aqueous extract (Cja150). The animals were treated once dailyby 
intra-gastric gavages for 50 consecutive days. During the treatment, fasting glycemia was estimated at the beginning and every ten days. At the end of the experimental period, all the rats were fasted over 24 hours placed individually on metabolic cages. Urines were collected in tubes containingxylol, quantified and used for biochemical analyses (total proteins, creatinin, ions).

Under mild ether anaesthesia, all the rats were thereafter sacrificed. Blood was collected into heparinised and centrifuge tubes. The collected blood from heparinised tubes was use for the preparation of hemolysates and the one from centrifuge tubes was allowed to clot during 5 minutes, then centrifuged $(3000 \mathrm{rpm}, 10 \mathrm{~min})$ for serum separation. Clear serum obtained was used for biochemical analyses (total protéins, créatinin, ions, thiol proteins, and catalase). The kidney was excised immediately, thoroughly washed in ice cold saline and used for the preparation of tissue homogenates.

\section{- Blood glucose levels}

Blood glucose level was measured at the beginning of the experiment and after every 10 days, using a glucometer Glucoplus ${ }^{\mathrm{TM}}$. Blood sample was obtained from the tail tip of fasted rats.

\section{- Renal function}

In serum and 24 hours collected urine, creatinin, sodium, potassium, chloride, magnesium, and calcium ions were estimated by colorimetric methods with commercially available test kits according to the manufacturer's recommendations (Fortress diagnostic UK). Seric and urinary total protein was determined by the Biuret method using Fortress test kit. All these parameters were quantified through the absorbance of the sample and standard, using UV-visible spectrophotometer (Genway, 6505 UV-visible).

\section{- Peripheral and central neurogenic pathological changes}

At the end of treatment, the peripheral and central neurogenic attack was evaluated by the pain sensibility of the rats using the analgesimeter and tail flick tests respectively [11].

In analgesimeter test, the animal right posterior leg was placed on a gradual and constant pressure apparatus (UGO BASILE analgesimetre, $16 \mathrm{~g} / \mathrm{s}$ ). The pain was induced by increasing pressure until animal retracts its leg to escape from pain.

To evaluate the central neurogenic attack, pain was induced in animals by immersing two-third of the tail in water bath at $55^{\circ} \pm 1^{\circ} \mathrm{C}$. The running time from the beginning of immersion to the thoroughly retract of animal tail from water bath was measured (the latency of tail flick).

\section{Antioxidant activity and biochemical analysis}

At the end of the treatment, antioxidant enzymes (SOD, catalase) activity, thiol proteins and total proteins were determined in kidney homogenates, hemolysat and serum. To prepare tissue homogenate, kidney was homogenized in $50 \mathrm{mM}$ Tris- $\mathrm{HCl}$ buffer ( $\mathrm{pH} 7.4)$, and then centrifuged $(10,000 \mathrm{rpm}, 15 \mathrm{~min})$; the supernatant obtained was used for various biochemical estimations. Hemolysate was prepared from heparinized blood as follow: $2 \mathrm{~mL}$ of saline solution were added to $100 \mu \mathrm{L}$ of blood, then centrifuged ( $3400 \mathrm{rpm}, 5 \mathrm{~min})$ and the supernatant separated from the clot. The process was repeated till the supernatant became clear, then $2 \mathrm{~mL}$ of distilled water were added to clot and centrifuged (15000 rpm, $30 \mathrm{~min}$ ); the supernatant obtained was used as hemolysate to estimate antioxidant enzymes activity [12]. Superoxide dismutase (SOD) activity was determined according to the method of Mirsa and Fridovich [13]. Catalase activity was assayed using the method of Sinha [14].Thiol proteins content was measured using Ellman's method [15].Tissue total protein concentration was estimated by the Biuret method using Fortress test kit.

\section{Statistical analysis}

The results are expressed as mean $(\bar{X}) \pm$ standard error of mean (S.E.M). The results were statistically analyzed by one way analysis of variance (ANOVA) associated with Turkey test followed by Dunnett test, using the computer GraphpadInstat Software. The difference between and within various groups was significant with $\mathrm{P}<0.05$. 


\section{Results}

Crinum jagus aqueous andhydroethanolic extracts effects

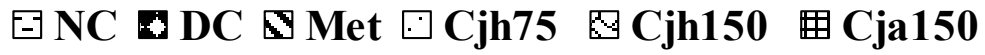

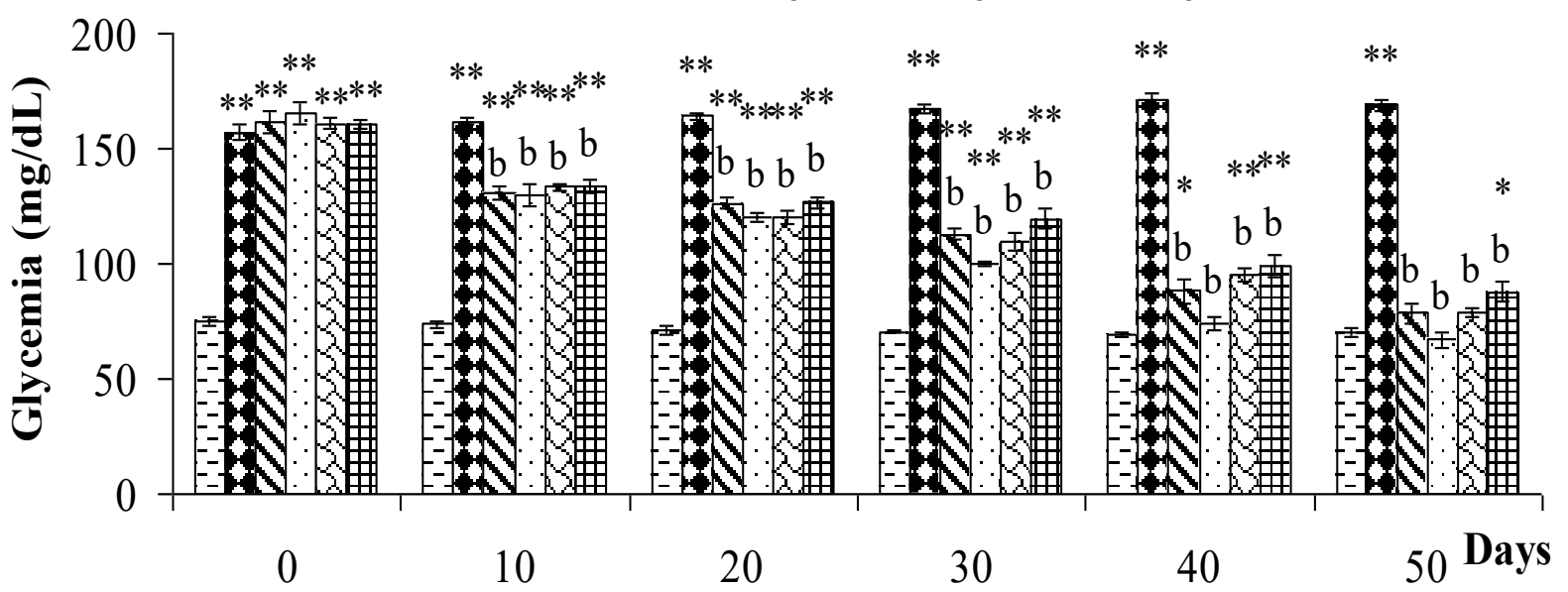

Figure 1: Glycemiaof rats during 50 days of once daily treatment. NC: normal control rats; DC: diabetic control rats; diabetic rats treated with $C$. jagus hydroethanolic extract $75 \mathrm{mg} / \mathrm{kg}$ (Cjh75), $150 \mathrm{mg} / \mathrm{kg}$ (Cjh150), C. jagus aqueous extract $150 \mathrm{mg} / \mathrm{kg}$ (Cja150) and metformine $38 \mathrm{mg} / \mathrm{kg}$ bw (Met). Significant difference: ${ }^{*} \mathrm{p}<0.05,{ }^{* *} \mathrm{p}<0.01$ compared to NC; ${ }^{b} \mathrm{p}<0.01$ compared to DC. $\mathrm{n}=5$ rats/group.
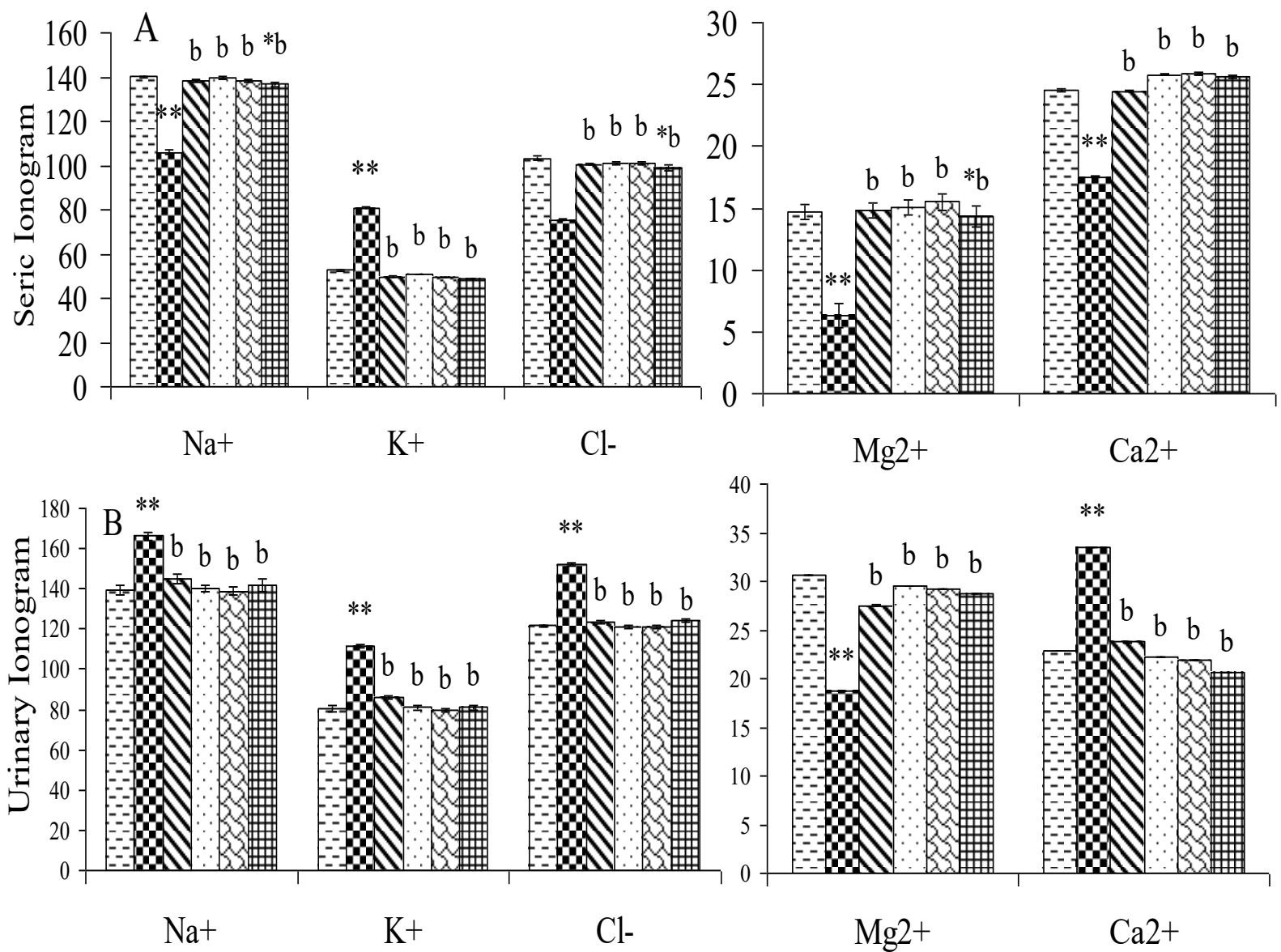

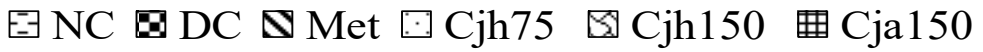

Figure 2: Seric (A) and urinary (B) electrolyte $\left(\mathrm{Na}^{+}, \mathrm{Cl}^{-}: \mathrm{mmol} / \mathrm{L} ; \mathrm{K}^{+}, \mathrm{Mg}^{2+}, \mathrm{Ca}^{2+}: \mathrm{mmol} / \mathrm{L} \cdot 10^{-1}\right)$ profilof rats at the end of once daily treatment for 50 days. NC: normal control rats; DC: diabetic control rats; diabetic rats treated with $C$. jagus hydroethanolic extract $75 \mathrm{mg} / \mathrm{kg}(\mathrm{Cjh} 75), 150 \mathrm{mg} / \mathrm{kg}$ (Cjh150), C. jagus aqueous extract $150 \mathrm{mg} / \mathrm{kg}$ (Cja150) and metformine $38 \mathrm{mg} / \mathrm{kg}$ bw (Met). $\mathrm{n}=5$ rats/group. Significant difference: ${ }^{* *} \mathrm{p}<0.01$ compared to $\mathrm{NC} ;{ }^{\mathrm{b}} \mathrm{p}<0.01$ compared to DC. 


\section{- Blood glucose levels}

During the 50 days of the treatment the DC glycemia remained very high when compared to normal control $(169 \pm 2.4$ vs $71.56 \pm 0.88 \mathrm{mg} / \mathrm{dL})$. The glycemia of diabetic rats treated with metformine (Met), hydroethanolic (Cjh75; Cjh150) and aqueous (Cja150) C. jagus extracts remarkably $(\mathrm{P}<0.01)$ decreased during the 50 days of treatment and particularly at the end $(-51.46 \pm 1.67 \%$; $59.28 \pm 2.82 \% ;-50.90 \pm 1.73 \%$ and $45.28 \pm 3.35 \%$ respectively). The decrease was more pronounced with hydroethanolic extract; the Cjh75 glycemia became comparable to NC as from the $40^{\text {th }}$ day $\left(74 \pm 1.32\right.$ and $69.2 \pm 2.89 \mathrm{mg} / \mathrm{dL}$ respectively) up to the $50^{\text {th }}$ day $(67 \pm 3.45 ; 70 \pm 1.7 \mathrm{mg} / \mathrm{dL}$ respectively); while Cjh150 and Met glycemia became no significantly different to NC by the end of the treatment (Figure 1).

\section{- Renal function}

Diabetes induced significant $(\mathrm{P}<0.01)$ total proteinemia and creatininuria decrease, creatininemia, urine volume and total proteinuria increase (Table 1). The blood level of $\mathrm{Na}^{+}, \mathrm{Mg}^{2+}, \mathrm{Ca}^{2+}, \mathrm{Cl}^{-}$and the urine level of $\mathrm{Mg}^{2+}$ decreased when the blood level of $\mathrm{K}^{+}$and the urine level of $\mathrm{Na}^{+}, \mathrm{K}^{+}, \mathrm{Ca}^{2+}$, $\mathrm{Cl}^{-}$increased in significant $(\mathrm{P}<0.01)$ way (Figure 2). After 7 weeks (50 days) treatment, the $C$. jagushydroethanolic (75 and $150 \mathrm{mg} / \mathrm{kg} \mathrm{bw})$ and aqueous $(150 \mathrm{mg} / \mathrm{kg} \mathrm{bw})$ extracts, as metformin, have markedly restored the different blood and urinary parameters and brought their level to the normal value: reduced the blood level of creatinin, $\mathrm{K}^{+}$and the urine volume, total proteins, $\mathrm{Na}^{+}, \mathrm{K}^{+}$, $\mathrm{Ca}^{2+}, \mathrm{Cl}^{-}$; raised the blood value of total proteins, $\mathrm{Na}^{+}, \mathrm{Mg}^{2+}, \mathrm{Ca}^{2+}, \mathrm{Cl}^{-}$and the urinary level of creatinin and $\mathrm{Mg}^{2+}$ (Table 1; Figure 2).

Table 1: Blood and urinary parameters (total proteins: $\mathrm{g} / \mathrm{L}$, creatinin: $\mathrm{mg} / \mathrm{dL}$, urine volume: $\mathrm{mL} / 24$ hours) of rats at the end of 50 days treatment once daily.

\begin{tabular}{cllllll}
\hline & NC & \multicolumn{1}{c}{ DC } & \multicolumn{1}{c}{ Met } & Cjh75 & Cjh150 & Cja150 \\
\hline Total proteins & $67.64 \pm 2.47$ & $34.98 \pm 2.89^{* *}$ & \multicolumn{1}{c}{ Serum } \\
Creatinin & $0.32 \pm 0.01$ & $0.61 \pm 0.01^{* *}$ & $0.37 \pm 0.01^{\mathrm{b}}$ & $0.28 \pm 0.02^{\mathrm{b}}$ & $0.32 \pm 0.02^{\mathrm{b}}$ & $0.39 \pm 0.03^{\mathrm{b}}$ \\
\hline \multicolumn{7}{c}{ Urine } \\
\hline 24 hrs volume & $6.00 \pm 0.50$ & $15.40 \pm 0.97^{* *}$ & $9 \pm 0.31^{\mathrm{b}}$ & $8.60 \pm 0.50^{\mathrm{b}}$ & $8.80 \pm 0.37^{\mathrm{b}}$ & $9.80 \pm 0.58^{* \mathrm{~b}}$ \\
Total proteins & $0.15 \pm 0.03$ & $0.82 \pm 0.06^{* *}$ & $0.25 \pm 0.05^{\mathrm{b}}$ & $0.15 \pm 0.03^{\mathrm{b}}$ & $0.16 \pm 0.03^{\mathrm{b}}$ & $0.19 \pm 0.03^{\mathrm{b}}$ \\
Creatinin & $10.97 \pm 0.28$ & $5.75 \pm 0.25^{* *}$ & $9.82 \pm 0.27^{* \mathrm{~b}}$ & $10.45 \pm 0.18^{\mathrm{b}}$ & $10.30 \pm 0.20^{\mathrm{b}}$ & $9.82 \pm 0.16^{* \mathrm{~b}}$
\end{tabular}

NC: normal control rats; DC: diabetic control rats; diabetic rats treated with C. jagus hydroethanolic extract $75 \mathrm{mg} / \mathrm{kg}$ (Cjh75), $150 \mathrm{mg} / \mathrm{kg}$ (Cjh150), C. jagus aqueous extract $150 \mathrm{mg} / \mathrm{kg}$ (Cja150) and metformine $38 \mathrm{mg} / \mathrm{kg}$ bw (Met). $\mathrm{n}=5$ rats/group. Significant difference: ${ }^{*} \mathrm{p}<0.05,{ }^{* *} \mathrm{p}<0.01$ compared to $\mathrm{NC} ;{ }^{\mathrm{b}} \mathrm{p}<0.01$ compared to compared to DC.

\section{- Peripheral and central neurogenic pathological changes}

In analgesimeter test, the pressure at which animal retracted its leg to escape from pain (force) remarkably increased in DC $(+93 \%)$. In diabetic rats treated with extract or metforminethe force significantly $(\mathrm{P}<0.01)$ decreased and was comparable to $\mathrm{NC}$ value (Figure $3 \mathrm{~A}): 4.8 \pm 0.3 \mathrm{~g} / \mathrm{s}$ (Cjh75), $5 \pm 0.2 \mathrm{~g} / \mathrm{s}$ (Cjh150), 5.3 $\pm 0.3 \mathrm{~g} / \mathrm{s}$ (Cja150), $5.9 \pm 0.3 \mathrm{~g} / \mathrm{s}(\mathrm{Met}), 5.8 \pm 0.2 \mathrm{~g} / \mathrm{s}$ (NC).

After 50 days of treatment, the DC latency time significantly $(\mathrm{P}<0.01)$ increased. Latency time of diabetic rats treated with hydroethanolic and aqueous extracts or Met remarkably decreased and was comparable to NC: $3.03 \pm 0.13 \mathrm{sec}$ (Cjh75), 3.25 $\pm 0.3 \mathrm{sec}$ (Cjh150), 3.64 $\pm 0.25 \mathrm{sec}$ (Cja150), $3.45 \pm 0.4 \mathrm{sec}$ (Met), $2.57 \pm 0.18 \mathrm{sec}(\mathrm{NC})$ (Figure 3B).

\section{- Antioxidant parameters}

After 50 days treatment, the antioxidant parameters (catalase: CAT and SOD activity in hemolysate and in kidney, thiol proteins concentration in serum), significantly decreased in DC:respectively $(84.60 \pm 4.62 \mu \mathrm{M} / \mathrm{mg}$ and $0.66 \pm 0.03 \mathrm{U} / \mathrm{mg}$ CAT and SOD (DC) vs. $142.30 \pm 3.76 \mu \mathrm{M} / \mathrm{mg}$ and $2.62 \pm 0.14$ $\mathrm{U} / \mathrm{mg}$ (NC) in the hemolysate; $62.75 \pm 4.07 \mu \mathrm{M} / \mathrm{mg}$ and $0.64 \pm 0.03 \mathrm{U} / \mathrm{mg}$ (DC) vs. $168.75 \pm 2.97$ $\mu \mathrm{M} / \mathrm{mg}$ and $2.71 \pm 0.03 \mathrm{U} / \mathrm{mg}$ (NC) in the kidney.The extracts and the metforminebrought the SOD both in the hemolysate and the kidney to normal values. Catalase of diabetic rats treated with hydroethanolic extract significantly $(\mathrm{P}<0.01)$ increased in hemolysate $(127.52 \pm 0.05 \mathrm{Cjh} 75$, 131.20 $\pm 3.88 \mu \mathrm{M} / \mathrm{mgCjh} 150)$ and kidney $(162.44 \pm 1.97 \mathrm{Cjh} 75,167.12 \pm 2.45 \mu \mathrm{M} / \mathrm{mg} \mathrm{Cjh} 150)$, and was 
comparable to $\mathrm{NC}$ catalase. The hemolysate and the kidney catalase level in diabetic rats treated with Met or Cja150 also increased significantly $(\mathrm{P}<0.01)$ but remained significantly $(\mathrm{P}<0.05)$ higher than the NC (Table 2).
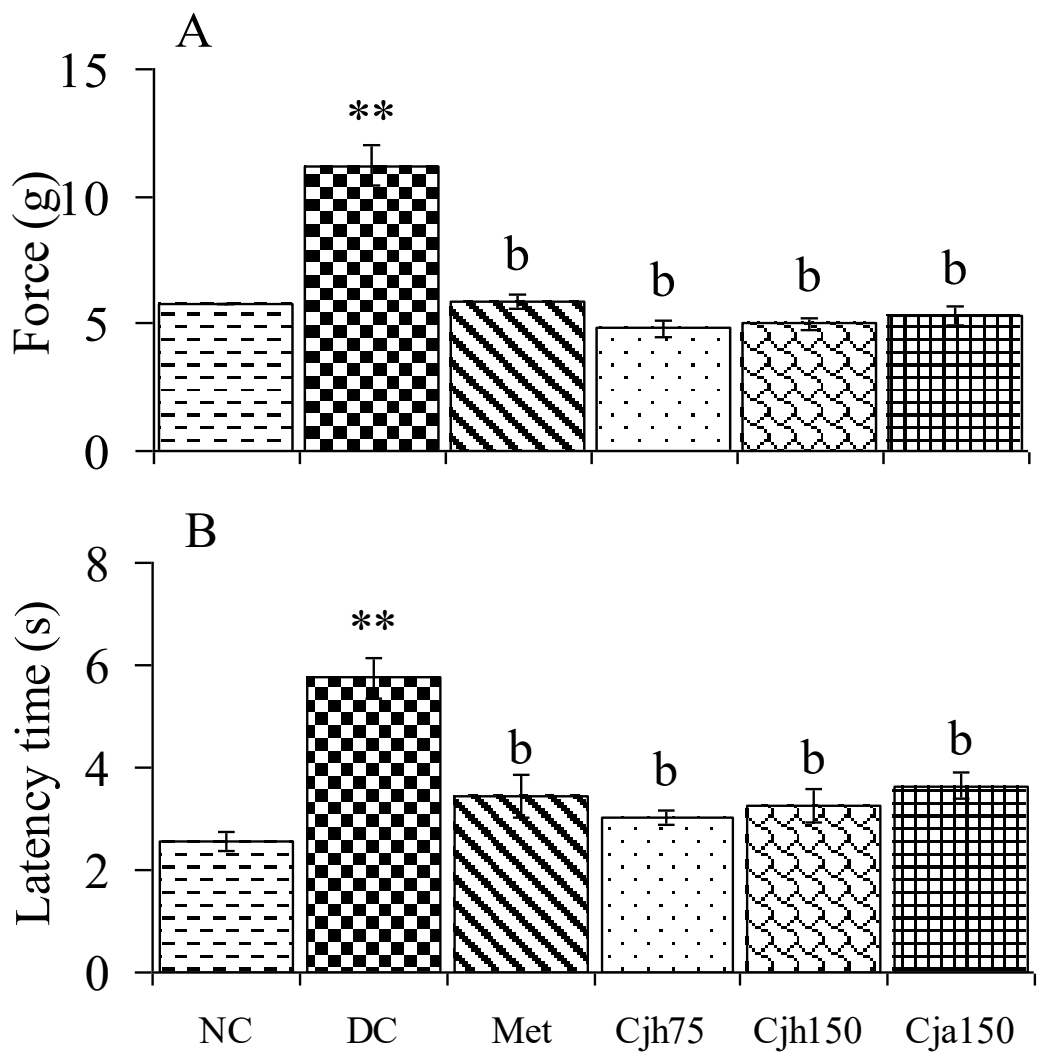

Figure 3: Sensibility of rats to pain induced by pressure (A) and heat (B) at the end of once daily treatment for 50 days. NC: normal control rats; DC: diabetic control rats; diabetic rats treated with C. jagus hydroethanolic extract $75 \mathrm{mg} / \mathrm{kg}$ (Cjh75), $150 \mathrm{mg} / \mathrm{kg}$ (Cjh150), C. jagus aqueous extract $150 \mathrm{mg} / \mathrm{kg}$ (Cja150) and metformine $38 \mathrm{mg} / \mathrm{kg}$ bw (Met). $\mathrm{n}=5$ rats/group. Significant difference: $* * \mathrm{p}<0.01$ compared to $\mathrm{NC} ;{ }^{b} \mathrm{p}<0.01$ compared to DC.

The DC thiol proteins seric level was significantly $(\mathrm{P}<0.01)$ lower than NC level. The $\mathrm{Cjh} 75, \mathrm{Cjh} 150, \mathrm{Cja} 150$ and Met have significantly increased the thiol proteins $(247.30 \%, 319.550$ $\%, 209.25 \%$ and $216.34 \%$ respectively). The hydroethanolic extract was more effective than the metformin and aqueous extract. The Met and Cja150 thiol proteins remained significantly $(\mathrm{P}<0.05)$ lower than NC (Table 2).

Table 2: Hemolysate and kidney antioxidant parameters (SOD: U/mg of protein, catalase: $\mu \mathrm{M}$ of $\mathrm{H}_{2} \mathrm{O}_{2}$ consumed $/ \mathrm{min} / \mathrm{mg}$ of protein), and sericthiol proteins (nM/mg of protein) of rats after 50 days of treatment.

\begin{tabular}{|c|c|c|c|c|c|c|}
\hline & $\mathrm{NC}$ & DC & Met & Cjh75 & Cjh150 & Cja150 \\
\hline \multicolumn{7}{|c|}{ Hemolysate } \\
\hline SOD & $2.62 \pm 0.14$ & $0.66 \pm 0.03 * *$ & $2.34 \pm 0.06^{b}$ & $2.34 \pm 0.05^{b}$ & $2.51 \pm 0.06^{b}$ & $2.45 \pm 0.08^{b}$ \\
\hline CAT & $142.30 \pm 3.76$ & $84.60 \pm 4.62 * *$ & $121.10 \pm 3.23^{* \mathrm{~b}}$ & $127.52 \pm 3.72^{b}$ & $131.20 \pm 3.88^{b}$ & $123.06 \pm 3.50^{* b}$ \\
\hline \multicolumn{7}{|c|}{ Kidney } \\
\hline SOD & $2.71 \pm 0.03$ & $0.64 \pm 0.03 * *$ & $2.61 \pm 0.04^{b}$ & $2.75 \pm 0.04^{b}$ & $2.77 \pm 0.05^{b}$ & $2.66 \pm 0.07^{b}$ \\
\hline CAT & $168.75 \pm 2.97$ & $62.75 \pm 4.07 * *$ & $152.90 \pm 4.02 * \mathrm{~b}$ & $162.44 \pm 1.97^{b}$ & $167.12 \pm 2.45^{\mathrm{b}}$ & $158.63 \pm 3.85^{b}$ \\
\hline \multicolumn{7}{|c|}{ Serum } \\
\hline $\begin{array}{c}\text { Thiol } \\
\text { proteins }\end{array}$ & $2.28 \pm 0.10$ & $0.61 \pm 0.06 * *$ & $1.92 \pm 0.06^{* b}$ & $2.11 \pm 0.06^{\mathrm{b}}$ & $2.55 \pm 0.06^{\mathrm{b}}$ & $1.88 \pm 0.05^{* b}$ \\
\hline
\end{tabular}

$\mathrm{NC}$ : normal control rats; DC: diabetic control rats; diabetic rats treated with $C$. jagus hydroethanolic extract $75 \mathrm{mg} / \mathrm{kg}$ (Cjh75), $150 \mathrm{mg} / \mathrm{kg}$ (Cjh150), C. jagus aqueous extract $150 \mathrm{mg} / \mathrm{kg}$ (Cja150) and metformine $38 \mathrm{mg} / \mathrm{kg} \mathrm{bw}(\mathrm{Met})$. $\mathrm{n}=5$ rats/group. Significant difference: ${ }^{*} \mathrm{p}<0.05,{ }^{*} \mathrm{p}<0.01$ compared to NC; ${ }^{\mathrm{a}} \mathrm{p}<0.05,{ }_{\mathrm{p}}^{\mathrm{b}}<0.01$ compared to DC. 


\section{Discussion}

The present work designed to investigate antioxidant and antidiabetic activities of Crinum jagus extracts on diabetic ratsMACAPOS 1. Diabetes was induced by high sugar diet (HSD) associated with dexamethasone (DXM) injection [16]. Hyperglycemia provoked by the combined effect of HSD and DXM was associated withSeric $\mathrm{Ca}^{2+}$ and $\mathrm{Mg}^{2+}$ decrease. More than metformin, $C$. jagus extract significantly decreasesglycemia of diabetic rats to normal valuesassociated with the significant increase of seric $\mathrm{Ca}^{2+}$ and $\mathrm{Mg}^{2+}$. This result suggested that, like metformin, extracts might not only decrease hepatic glucose production, and ameliorate the peripheral insulin sensitivity [17], but could also act by many other means than metformin. This result also led us to think that, extract could increase insulin secretion by increasing calcemia. Insulin secretion is a calcium dependant process [18]. When blood glucose levels increase, the glucose is transported inside with help of GLUT-4 transporters. This result confirmed, as suggested in previous work, that Crinum jagus extract might stimulate the release of insulin as glibenclamide [16]. Furthermore, calcium is important for insulin mediated intracellular processes in insulin responsive tissues. It is important for insulin receptor phosphorylation and proper signal transduction, and thus optimal GLUT-4 transporter activity [18]. Magnesium is also involved at multiple levels in insulin secretion, binding and activity [19]. Low magnesium in diet leads to impaired insulin secretion and action [20]. The increase of seric calcium and magnesium by Crinum jagus extracts might be very benefic for the decrease of diabetic glycemia and consequently for the treatment of diabetes. The glycemia decrease activity of different extracts could result from some antidiabetic chemical compounds found in those extracts such as polyphenol, flavonoid, triterpen, saponnin, antocyan, coumarin[7,21,22,23]. Either singly or in synergy with one another, the above mentioned components could have been responsible for the observed significant glycemia decrease activity of these extracts.

Negative fluctuation of protein, creatinin, electrolytes levels in serum and urine, observed in diabetic rats might result from kidney defect functional due to the hyperglycemia. Hyperglycemia induces microvascular degeneration which could affect kidney glomerula and capillary system and consequently might negatively affect the filtration, reabsorption and secretion functions of the kidney [24]. This could explain the increase of proteinuriaand creatinemia, decrease of creatinuria and proteinemia, and ionic imbalance observed in diabetic rats; indicating renal function impairment in diabetic rats MACAPOS-1. Treatment of diabetic rats with aqueous, hydroethanolic extract or metformin restored those parameters. The highest effect was observed with hydroethanolic extract. Increased proteinuria typically reflects the presence of advanced lesions in kidney disease [25]. The hyper creatinemia could result from a diminished renal function as creatinin is excreted by the kidney; this is known to be indicative of the injury of the nephrons [26]. The decrease of seric creatinin and urinary protein by $C$. jagus extracts led to think that $C$. jagus could ameliorate kidney damage which is one of diabetes complications, and thus, could indicate a nephroprotective effect of these extracts. $98 \%$ of $\mathrm{Ca}^{2+}$ filtered in glomerula is reabsorbed in kidney tubula[27]. Peritubular capillaries degeneration altered the tubular reabsorption and consequently, decreases seric ions levels. Calcemia decrease was associated with calciuria increase in diabetic rats. The increase of calcemia and decrease of calciuria by extracts could be linked to the restoration of tubular reabsorption function of the kidney. Besides, extracts could have alsoachieved this result by affecting the secretion or activity of parathyroid hormone which increases the renal tubular reabsorption of $\mathrm{Ca}^{2+}$ and promotes intestinal calcium absorption [28]. So the extracts increased the seric $\mathrm{Na}^{+}, \mathrm{Cl}^{-}, \mathrm{Ca}^{2+}$ and $\mathrm{Mg}^{2+}$ in diabetic rats, probably by improving the kidney tubular reabsorption. The excellent recovery of renal function expected with treatment of extracts could be due to the normal glycemia recovery of diabetic rats. Sustained hyperglycemia is the main cause of the changes in kidney function in diabetes mellitus [29]. Both seric and urine electrolytes were restored to normal levels by $C$. jagus extracts in similar manner to metformine.

Hyperglycemia in diabetic patients can increase the levels of free radicals [30]. Significant decrease of the superoxide dismutase (SOD), catalase and thiol proteins observed on the diabetic rats indicated the poor antioxidant defense system of those animals [31]. That decrease of SOD, 
catalase and thiol proteins may be due to enhanced free radical generation in diabetes. Furthermore, free radical mediated oxidative stress has been implicated in the pathogenesis of diabetes and its complications [32]. The SOD and the catalase (CAT) are the 2 major scavenging enzymes that remove toxic free radical in vivo. SOD protects tissues against oxygen free radical by catalyzing the removal of superoxide radical, converting it into hydrogen peroxide and molecular oxygen. The CAT intervenes in the reduction of hydrogen peroxide to water and oxygen thus protects the tissues from oxidative damage produced by hydrogen peroxide [33]. Thiol proteins play a major role in maintaining the antioxidant statue of the body. They are the major antioxidants in the body fluids which are known to reduce highly reactive free radical, thus protecting the biomolecules [30]. Oxidative stress is associated with diabetes. In induced diabetes rats MACAPOS1, the decrease of SOD and catalase activity in hemolysate and kidney, and the decrease of seric thiol proteins may result in a number of deleterious effects due to the accumulation of superoxide anion, hydrogen peroxide and many others reactive free radical. Moreover, the increase of reactive oxygen species generated in chronic renal failure patients are believed to decrease the thiol proteins; and yet the decrease of thiol proteins increases renal failure severity [32,34]. Little more than metformine and the aqueous extract, the hydroethanolic extract of $C$. jagus significantly increased SOD, catalase and thiol proteins in a dose dependent manner. Antioxidant capacities of the C. jagus extracts could be linked to their phytochemical components such as polyphenols, flavonoids, antocyanes, tannins which have antioxidant properties, and could confirm the in vitro antioxidant activities of the extracts [21].

In diabetic rats, the hyperglycemia might be the cause of peripheral and central neurological defects decreasing the sensibility to pain induced by pressure and by heat respectively. Neurological defects in diabetes include nerve conduction defects seen in different regions of the body [35]. Peripheral and central neurological sensibility decreased in diabetic rats, indicating respectively affect of those animals. In diabetes, diseases nerve affected not only the commonly peripheral nerves but also the cranial and the autonomic nerves. This could lead to the loss of sensation in the legs [24]. The significant increase of neurological sensitivity by the $C$. jagus extracts could be due to glycemia decrease. Besides, 2 alcaloides (hamayne and lycorine) extracted from C. jagus bulb inhibit acetylcholine esterase activity [36]. The combined effect of this inhibitory activity and calcemia increase, largely contribute to increase available acetylcholine; thus, increase not only the velocity of neurological transmission, but also hypoglycemia activity. Acetylcholine is a hypoglycemic neurotransmitter of parasympathic nervous system. The improvement of neurological sensibility might also be due to the antioxidant properties of the extracts since glucotoxicity in neurons leads to an increase in reactive species production [37].

\section{Conclusion}

The results showed that, both aqueous and hydroethanolique extracts of $C$. jagushave antioxidant, antidiabetic, antinephropathic and antineuropathicactivities in MACAPOS-1 induced diabetic rats. This finding justifies the use of the plant in traditional medicine for diabetes treatment. Hydroethanolic extract which effects were higher than aqueous extract could be use for the development of a standardized phytomedicine for the treatment of diabetes mellitus and more over its complications.

\section{Competing Interests}

The authors declare that there is no conflict of interests.

\section{Acknowledgements}

Authors sincerely thank the Institute of Medical Research and Medicinal Plants Studies (IMPM), Yaounde, Cameroon for providing for providing part financial support to carry out the research work and the laboratory facilities during this study. 


\section{References}

[1] American Diabetes Association, ADA.Diagnosis and classification of diabetes Mellitus, Diab. Care 32 (2013) 62-67.

[2] V.A. Kangralkar, D.P. Shivrajang, R.M. Bandivadekar, Oxidative stress and diabetes: A review, Int. J. Pharm. Appl. 1 (2010) 38-45.

[3] International Diabetes Federation (IDF). Diabetes atlas, $6^{\text {th }}$ edition, Brussels, Belgium, Int. Diab. Fed., 2013.

[4] J. Haleng et al., Le stress oxidant, Rev. Méd. Liège. 62 (2007) 628-638.

[5] S. Rambhade et al., Diabetes mellitus: Its complications, factors influencing complications and prevention-An overview. J. Chem. Pharm. Res.2 (2010) 7-25.

[6] D.G. Grahame-Smith, J.K. Aronson, Clinical pharmacology and drug therapy $3^{\text {rd }}$ edition, Oxford University Press Inc, New York, 2002.

[7] N. Khera, A. Bhatia, Medical plants as natural antidiabetic Agents, Int. J. Pharm. Sci. Res. 5 (2014) 713-729.

[8] O.J. Ode, I.U. Asuzu, The anti-snake venom activities of the methanolic extract of Crinumjagus (Amaryllidaceae), Toxiconomy. 43 (2006) 331-342.

[9] J.A. Smith et al., Federation of European Laboratory Animal Science Associations: (FELASA), Working Group on Ethical Evaluation of Animal Experiments. Principles and practice in ethical review of animal experiments across Europe: summary of the report of a FELASA working group on ethical evaluation of animal experiments, Lab. Anim. 41 (2007) 143-160.

[10]R. Kamgang et al., Réactivité glycémique et évolution pondérale des rats soumis à de diètes locales hypercaloriques, J. Cam. Acad. Sci. 6 (2006) 187-193.

[11]P. Gomathi et al., Evaluation of the Analgesic and Anti-inflammatory Properties of Methanol Extract of Artanema sesamoides Benth Roots in Animal Models, Asian J. Pharm. Biol. Res. 1 (2011) 447-453.

[12]A. Srinivasan, P. Venugal, P.V. Menon, Protection of pancratic $\beta$-cell by the potential antioxidant bis o hydroxyl cinnamoyl methane, analogue of natural curcuminoid in experimental diabetes, J. Pharm. Pharm. Sci. 6 (2003) 327-333.

[13]H.P. Misra, I. Fridovich, Estimation of superoxide dismutase, J. Biol. Chem. 247 (1972) 317078.

[14]K.A. Sinha, Colorimetric assay of catalase, Anal biochem. 47 (1972) 389-395.

[15]A.M. Masoud et al., Alterations in Antioxidant Defense System in the Plasma of Female Khat Chewers of Thamar City, Yemen. Jordan J. Biol. Sci. 2 (2012) 129-133.

[16]C. Mvongo et al., Effect of ethanol-water extract of Crinum jagus on glycemia reactivity in dexamethasone-induced diabetic rat MACAPOS 1, Int. J. Pharm. Res. Bio-Sci. 3 (2014) 157167.

[17] M.D. Itamar Raz, Guideline Approach to Therapy in Patients With Newly Diagnosed Type 2 Diabetes, Diab. Care. 36 (2013) 139-144.

[18]N. Kanchana, P. Saikumar, Serum calcium levels in type 2 diabetes mellitus, J. Dent. Med. Sci. 13 (2014) 01-03.

[19]A.S. Khubchandani, H. Sanghani, Study of serum magnesium and hbalc in diabetic patients along with changes in their lipid profiles, Ind. J. Clin. Pract. 23 (2013) 717-719.

[20] S.C. Larsson, A. Wolk, Magnesium intake and risk of type 2diabetes: a meta-analysis, J. Int. Med. 262 (2007) 208-214.

[21]C. Mvongo et al., Phytochemical studies and in vitro antioxidant potential of two different extracts of crinum jagus, Int. J. Pharm. Sci. Res. 6 (2015) 1000-1006.

[22]D.K. Burdi, S. Qureshi, A.B. Ghanghro, An overview of available Hypoglycemic Triterpenoids and Saponins to cure Diabetes mellitus, Int. J. Adv. Life Sci. 1 (2014) 119-128.

[23]B.S. Nayak et al., Hypoglycemic activity of Chrysobal (Fat-pork) fruit extract in diabetes induced rats, Asian J. Pharm. Biol. Res. 1 (2011) 512-517.

[24] M. Nair, Diabetes mellitus, part 1: Physiology and complications, Brit. J. Nur. 16 (2007) 184188. 
[25] M.S. Roy, Proteinuria in African Americans with type 1 diabetes, J. Diab. Compli. 18 (2004) 69-77.

[26] S.O. Majekodunmi, A.O. Oyagbemi, O.A. Odeku, Ameliorative effects of the ethanolic seed extract of Mucunapruriens in alloxan-induced biochemical alteration in male Wistar rats, Pharmacologia. 5 (2014) 177-183.

[27]A. Shukla, S. Priyadarshi, I. Qamar, Involvement of calcium and vitamin c in type 2 diabetes, IOSR J. Pharm. 2 (2012) 009-020.

[28]I.J. Chigozie, I.C.Chidinma, Positive moderation of the hematology, plasma biochemistry and ocular indices of oxidative stress in alloxan-induced diabetic rats, by an aqueous extract of the leaves of Sansevieria liberica Gerome and Labroy, Asian Pac. J. Trop. Med. 1 (2013) 27-36.

[29]C.T. Musabayane, The effects of medicinal plants on renal function and blood pressure in diabetes mellitus, Cardiovasc. J. Africa. 23 (2012) 462-468.

[30] S.M. Awanti, P.S. Baruah, M. Prakash, Serum and urine protein thiols in type 2 diabetes mellitus, Ind. J. Physiol. Pharmacol. 53 (2009)185-188.

[31]H.A. Hassan Mostafa, Lipid peroxidation end-products as a key of oxidative stress: effect of antioxidant on their production and transfer of free radicals. INTECH Open Access Publisher, 2012, http://dx.doi.org/10.5772/45944.

[32] M. Prakash et al., Total thiols: Biomedical importance and their alteration in various disorders, Online J. health allied Sci. 8 (2009) 1-9.

[33] S. Indradevi et al., Ethanolic extract of Crinum asiaticum attenuates hyperglycemia-mediated oxidative stress and protects hepatocytes in alloxan induced experimental diabetic rats, J. King Saud. Univ.-Sci. 24 (2012) 171-177.

[34]C.I. Sajeeth, P.K. Manna, R. Manavalan, Antioxidant activity of polyherbal formulation on streptozotocin induced diabetes in experimental animals, Pelagia Res. Lib. 2 (2011) 220-226.

[35] M.V. Ravishankar, H.N. Rohini, Effect of Clitoria ternatea (linn) plant root extract on the neurons offrontal cortex and dentate gyrus of young diabetic rats - A preliminary investigation, Int. J. Sci. Technol. 16 (2013) 1138-1144.

[36]A. Adegbulugbe, Cholinesterase inhibitory properties of alkaloids from two Nigerian crinum species, Phytochem. 65 (2004) 2893-2896.

[37] S. Saeed, A. Mohsen, S. Fariborz, Ameliorative effect of Saffron aqueous extract on hyperglycemia, hyperlipidemia and oxidative stress on diabetic encephalopathy in streptozotocine induced experimental diabetes mellitus, Biomed Res. Int. 2014, http://dx.doi.org/10.1155/2014/920857. 